\title{
Histopathological Feature of Acute Appendicitis in Kerman-Iran from 1997 to 2003
}

\author{
Fatemeh Nabipour \\ Department of Pathology, Kerman Medical School, Nabipour Pathology Laboratory \\ Esteghlal Medical Building, Esteghlal Street, Kerman, Iran
}

\begin{abstract}
Acute appendicitis is one of the most common surgical conditions that affect about seven percent of the population. The histopathologic stages of appendicitis are important to regarding prognosis. To evaluate pathologic features of appendix after operation, this study was designed. 2753 appendices specimen that had been received to department of pathology of two major hospitals in Kerman-Iran during five years periods were reviewed by two pathologist and classification was performed by followed: Normal, early acute, acute, suppurative or purulent, gangrenous and perforated appendicitis. There were $54.6 \%$ males, the average age of patients was $24.9+/-13.3$ (mean+/-SD), that $76.6 \%$ was under 30 years old. $34.2 \%$ of reports were normal histopathologically. The accuracy rate of acute appendicitis was $65.8 \%$. Perforation observed to $0.8 \%$. There was significant difference between sex and stage of development of appendicitis. Seasonal incidence was difference in various histopathology views, significantly. Finally, acute appendicitis was more frequent in men than women and was increase by age specially 19-30 years. Our results showed appendicitis was more frequent and higher in stage at winter.
\end{abstract}

Key words: Acute Appendicitis, Pathology, Kerman

\section{INTRODUCTION}

Acute appendicitis is the most common disease of surgical field in world wide and affects about seven percent of the population. Surgeons have many challenges about diagnosis of it, yet. Diagnosis of acute appendicitis is made primarily on the basis of the history and the physical examination, with additional assistance from laboratory and radiographic findings [1]. However histopathologic studies are the gold standards for diagnosis of acute appendicitis [2]. This makes the appendix one of the more commonly received specimens at pathology department. Histopathologic features of appendicitis have been diagnosed after operation, so a great number of patients are operated without finding regarding to severe involvement. On the other hand, pathologists have controversy in review and reporting of the specimens of appendix especially in normal features. Mbembati and coworkers reported $19.6 \%$ of normal appendices, $26.7 \%$ chronic and $48.9 \%$ acute appendicitis [3].

Therefore, this study designed to evaluate histopathologic features of appendices received to laboratory and described distribution of appendicitis staging during 5 years period on Iran.

MATERIAL AND METHOD

We reviewed the charts of all patients who underwent appendectomy over a 5 years period from January 1997 to January 2003. All pathologic reports from two major educational hospital of Kerman medical schools were reviewed and 2753 retrospective appendices pathology reports were withdrawn. All specimens had been Formalin-fixed, Paraffin-based and at least reviewed by two pathologists. We divided the reports into g groups:

* Normal appendix without any pathologic changed.

* Early acute appendicitis with intraluminal and mucosal inflammation.

* Acute focal appendicitis with acute mucosal and submucosal inflammation.

* Acute suppurative appendicitis.

* Gangrenous appendicitis.

* Perforated appendicitis [2, 4].

For all cases, the demographic variables were gathered. SPSS-11.5 software was used to analyze data. The Man-Whitney test was used to determine difference of pathologic feature between genders. Spearman's correlation coefficient (rho) was used to reveal the degree of linear correlation between staging of appendicitis and age of patients. For each of proportions confidence interval was calculated and in the all tests $\mathrm{P}<0.05$ seems significantly.

\section{RESULTS}

From January 1997 to January 2003, 2753 appendectomies were performed with preoperative 
Table 1: The Distribution of Histopathologic Features by Sex

\begin{tabular}{lrrr}
\hline Sex Pathology & Male & Female & Total \\
\hline Normal & 411 & 531 & 942 \\
Early & 136 & 118 & 254 \\
Acute focal & 229 & 157 & 386 \\
Suppurative & 584 & 343 & 927 \\
Gangrenous & 131 & 90 & 221 \\
Perforated & 13 & 10 & 23 \\
Total & 1504 & 1249 & 2753 \\
\hline
\end{tabular}

Mann-Whitney test: $\mathrm{U}=779092 \quad \mathrm{P}<0.0005$

Table 2: The Distribution of Histopathologic Features by Season

\begin{tabular}{lrrrrr}
\hline Season Pathology & Spring & Summer & Autumn & Winter & Total \\
\hline Normal & 252 & 205 & 235 & 250 & 942 \\
Early & 61 & 55 & 70 & 68 & 254 \\
Acute focal & 73 & 73 & 104 & 136 & 386 \\
Suppurative & 255 & 241 & 230 & 201 & 927 \\
Gangrenous & 54 & 60 & 49 & 58 & 221 \\
Perforated & 2 & 9 & 9 & 3 & 23 \\
Total & 697 & 643 & 697 & 716 & 2753 \\
\hline
\end{tabular}

Kruskal-Wallis test: $\quad$ Chi2 $=8.895 \quad \mathrm{P}=0.031$

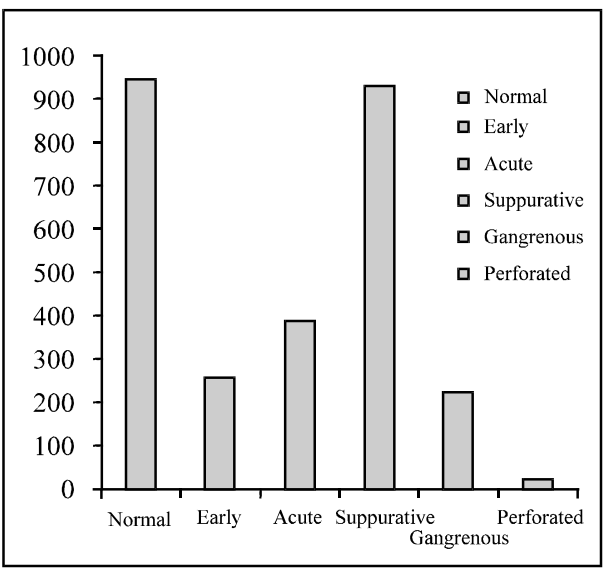

Fig. 1: The Frequency of Histopathologic Stages

diagnosis of acute appendicitis in two major hospitals at Kerman city-Iran. There were 1504 cases males $(54.6 \%)$ and $1249(45.6 \%)$ females. The ages ranged from 1 to 90 years with mean (SD) of 24.9 (13.3) years, whereas age o $76.6 \%$ of cases were under 30 years old. The incidence of negative appendectomy was $34.2 \%$ and the rate of perforated appendicitis was $0.8 \%$ (Fig. 1). Frequency of Inflammatory histopathology was higher in male group $($ Eta $=0.153)($ Table 1$)$.

There was a pool correlation between age groups and type of diagnosis (Spearman rho=0.07, $\mathrm{P}<0.0005$ ).

Seasonal incidence was significantly difference in the various histopathologic views and rates of acute appendicitis were higher in the autumn and winter (Fig. 2). Accuracy of preoperative diagnosis figured out $65.8 \%$.

\section{DISCUSSION}

This finding was performed to identify presentation of various types of appendectomy histopathology and accuracy of appendicitis diagnosis. In the period 1997-2003, an estimated 4200-4600 appendectomies were performed in Kerman, crude incidence rate estimated 10 per 1000 population. It is lower than united state 26 per 1000 [5].

In this study of 2753 consecutive resected appendicitis, there was complete agreement between pathologists. 942 cases were normal that was higher in females than in males. In the Addiss' and coworkers study, the frequency was 2.5 times high in female aged 15-24 years than that for males of the same age [5]. Totally, it seems diagnostic accuracy was lower for females than for males. This finding observe in the other studies, too $[3,6]$.

The age-specific incidence of acute appendicitis followed a similar pattern for males and females, though males have higher rates at virtually all ages [5]. Our finding showed a poor positive correlation between age groups and stage of appendicitis. It is acceptable that incidence of appendicitis occur in adolescent and young people $[1,5]$. The most frequent pathology of appendicitis was suppurative appendicitis. The rate of perforated appendicitis was $0.8 \%$ and gangrenous appendicitis was $8 \%$ that were lower than other studies. The literature reports that percentages of patients with perforated and /or gangrenous appendicitis were ranges from $16 \%$ to $43 \%$ [7-13]. Just as, it reveal gangrenous and perforated types of appendicitis in our study are lower than that the other registered findings. Perhaps it 
refers to operate doubtful patients to appendicitis as soon as possible in Kerman.

One of interesting finding in our study was relation between seasonal incidence and type of pathology. The frequencies regarding to progressive stage were greater in autumn and winter, but in Addiss' study appendectomy had increased during the summer month [5].

At the end, histopathologic features of appendix are very difficult sometimes and create difficulty to diagnose of stage of appendicitis [14]. Thus preparation of new cuts and slides and review by many pathologists is necessary because it is important to patient's prognosis and outcome.

\section{REFERENCES}

1. Lally, K.P., C.S. Cox and R.J. Andrassy, 2004. Appendix, In: Townsend, C.M., R.D. Beauchamp, B.M. Evers and K.L. Mattox, Sabiston textbook of surgery, $17^{\text {th }}$ Edn. Elsevier Sunders Co., Philadelphia, pp: 1381-1400.

2. Rosai, J., 2004. Rosai and Akerman surgical pathology, $9^{\text {th }}$ Edn., Mosby Co., China, pp: 757-61.

3. Mbembati, N.A., L.E. Lema, H.A. Mwakyoma and E.V Ussiri, 1996. Appendicitis in Dar es Salam, Histopathologic pattern. Cent. Afr. Med. J., 42: 68-70.

4. Carr, N.J., 2000. The pathology of acute appendicitis. Ann. Diagn. Pathol., 4: 46-58.

5. Addiss, D.G., N. Shaffer, B.S. Fowler and R.V. Tauxe, 1990. The epidemiology of appendicitis and appendectomy in the Unaited State. Am. J. Epidemiol., 132: 910-25.
6. Jones, K., A.A. Pena, E.L. Dunn, L. Nadalo and A.J. Mangram, 2004. Are negative appendectomies still acceptable? Am. J. Surg., 188: 748-54.

7. Temple, C.L., S.H. Hucherfort and W.J. Temple, 1995. The natural history of appendicitis in adults-a prospective study. Ann. Surg., 221: 278-81.

8. Elder, S., E. Nash, E. Sabo and et al., 1997. Delay of surgery in acute appendicitis. Am. J. Surg., 173: 194-8.

9. Wiliams, N. and M. Bello, 1998. Perforation rate relates to delayed presentation in childhood acute appendicitis. J.R. Coll. Surg. Edinb., 43: 101-2.

10. Wilson, D., S. Sinclair, W.A. MoCallion and S.R. Potts, 1994. Acute appendicitis in young children in the Belfast urban area 1985-92. Ulster. Med. J., 63: 3-7.

11. Calvieu, P.A., P. Junod and G. Chapuis, 1987. A prospective study of 776 cases of acutenontreumatic abdominal pain. Acute appendicitis and its diagnosis. Schweiz. Med. Wochenschr., 117: 1205-12.

12. Levy, R.D., E. Degiannis, A. Kantrovsky and et al., 1997. Audit of acute appendicitis in a black South African population. S. Afr. J. Surg., 35: 198-202.

13. Morrison, C.A., D.L. Greco and K.G. Torrengton, 2000. Pattern of appendicitis at forward deployed United State army hospital: The Korean experience. Curr. Surg., 57: 603-9.

14. Herd, M.E., P.A. Cross and D. Dutt, 1992. Histopathologic audit of acute appendicitis. J. Clin. Pathol., 45: 456-8. 